\title{
TLR/NCR/KIR: which one to use and when?
}

\section{Simona Sivori ${ }^{1}$, Simona Carlomagno ${ }^{1}$, Silvia Pesce ${ }^{1}$, Alessandro Moretta ${ }^{1}$, Massimo Vitale ${ }^{2}$ and Emanuela Marcenaro ${ }^{1}$ *}

${ }_{1}^{1}$ Dipartimento di Medicina Sperimentale, Centro di Eccellenza per le Ricerche Biomediche, Università degli Studi di Genova, Genova, Italy

2 IRCCS Azienda Ospedaliera Universitaria San Martino-IST, Istituto Nazionale per la Ricerca sul Cancro, Genova, Italy

Edited by:

Daniel Olive, INSERM UMR 891 Institut Paoli Calmettes, France

Reviewed by:

Daniel Olive, INSERM UMR 891 Institut Paoli Calmettes, France Miguel López-Botet, Hospital del Mar Medical Research Institute, Spain

\section{*Correspondence:}

Emanuela Marcenaro, Dipartimento di Medicina Sperimentale, Sezione di Istologia, Via G.B. Marsano 10,

Genova 16132, Italy

e-mail: emanuela.marcenaro@unige.it
By means of a complex receptor array, Natural killer (NK) cells can recognize variable patterns of ligands and regulate or amplify accordingly their effector functions. Such NK receptors include old, rather conserved, molecules, such as toll-like receptors (TLRs), which enable NK cells to respond both to viral and bacterial products, and newer and evolving molecules, such as killer Ig-like receptors and natural cytotoxicity receptors, which control NK cytotoxicity and are responsible for the elimination of virus-infected or tumor cells without damaging self-unaltered cells. In addition, to rapidly gain new functions NK cells also can acquire new receptors by trogocytosis. Thus, NK cells may have adapted their receptors to different functional needs making them able to play a key role in the modulation of critical events occurring in several compartments of human body (primarily in SLCs but also in decidua during pregnancy). In this review, we will discuss on how the various types of receptors can be used to address specific functions in different immunological contexts.

Keywords: NK cell, TLR, KIR, NCR, CCR7, anti-tumor response, anti-viral response, innate immunity

\section{INTRODUCTION}

Natural killer (NK) cells are innate lymphocytes present in all mammalian species capable of mediating multiple effector functions. NK cells express a number of receptors through which they can directly recognize microbial products, can sense aberrant/transformed cells [which lack constitutive self-human leukocyte antigen (HLA)-I molecules and express ligands for activating NK receptors], or even mediate regulatory functions (being an early source of cytokines) $(1,2)$.

Despite the original definition of NK cells based on their "natural" cytotoxicity against transformed cells in the absence of prior immunization, several studies indicate that NK cells require education/maturation process before killing and carrying out their biological functions (3).

Specialized NK subsets, which display distinct functions according to their typical cell-surface phenotype, exist. In particular, the CD56 ${ }^{\text {bright }} \mathrm{NK}$ cell subset presents little cytolytic activity but releases high amounts of cytokines, whereas CD56 ${ }^{\mathrm{dim}} \mathrm{NK}$ cell subset displays potent cytotoxicity but also high cytokine production in response to specific stimuli (4-6).

The former subset is characterized by the $\mathrm{CD} 16^{-} \mathrm{KIR}^{-} \mathrm{NKG} 2 \mathrm{~A}^{+}$ phenotype and largely predominates in lymph nodes, according to the expression of CCR7 (the homing receptor for secondary lymphoid compartments, SLCs) $(7,8)$, whereas the latter subset is $\mathrm{CD}_{16}{ }^{+} \mathrm{KIR}^{+}$and/or $\mathrm{NKG}_{2} \mathrm{~A}^{+}$and prevails in peripheral blood and inflamed tissues where they can be recruited, thanks to the expression of the CXCR1, CX3CR1, and ChemR23 chemokine receptors $(4,9,10)$.

Thus, during the early phases of an inflammatory response, CD56 ${ }^{\text {dim }}$ NK cells may be recruited into inflamed tissues in response to various chemokines. Notably, the extravasation of NK cells do not imply their activation, thus these cells, once reached inflammatory sites, need to be activated to carry out their full effector functions (9). Candidates for NK cell activation are cytokines, released by innate cells, which are known to interact with NK cells (e.g., IL12), and/or engagement of certain activating receptors, including toll-like receptors (TLRs) and/or natural cytotoxicity receptors (NCRs) (11-14).

The stimulatory activity mediated by these receptors can induce NK cell-mediated lysis of tumor/virus-infected cells, the release of pro-inflammatory cytokines and, importantly, can promote the interactions of NK cells with other innate cells (15-17). This latter event can help to boost the innate immune system and promote the development of efficient adaptive immune responses (18).

In this review, the contribution of the different types of NK cell receptors in NK cell activation and their cooperation has been analyzed. In addition, new mechanisms of cell communication that allow the acquisition of unexpected receptor functions and/or novel functional properties have been described $(7,19,20)$.

These novel aspects, probably occurring in response to environmental stress such as viral or bacterial infections, disclose new potential implications of NK cells in physiologic and pathologic conditions.

\section{TOLL-LIKE RECEPTORS}

Toll-like receptors belong to pattern-recognition receptors (PRRs), which have evolved to recognize conserved features of microbes, the so-called pathogen-associated molecular patterns (PAMPs) $(21,22)$. TLRs are expressed on NK cells independently of their state of activation and can synergize with chemokine- or cytokinemediated signals to activate NK cell function (Table 1A). Both NK cells and other innate cells express certain TLRs, thus allowing a coordinated response to the same pathogen-derived product. For example, viral dsRNA can act on TLR3 expressed by both myeloid dendritic cells (DCs) and NK cells, recruited by chemokine gradients to inflammatory sites. In the presence of IL12 (released by DCs 
Table 1 | (A) TLRs expressed by human NK cells and relative ligands: effect of their interaction; (B) NCRs expressed by human NK cells and relative ligands: effect of their interaction; (C) KIRs expressed by human NK cells and relative ligands: effect of their interaction.

Ligand(s) type Ligand(s) expression

\section{(A) TLR}

TLR2

TLR3

TLR5

Flagellin

TLR7/8

Single-stranded RNA

CpG DNA motifs

TLR9

Bacterial lipoprotein (BCG)

Double-stranded RNA

B7-H6

(B) NCR

NKp30

BAT3/BAG6

ECTV HA

V HA

NKp44 21spe-MLL5

Influenza virus-HA; Sendai virus-HN

PCNA

N.D.

N.D.

N.D.

NKp46

N.D.

Influenza virus-HA; Sendai virus-HN

N.D.

NDV-HN

N.D.
Bacteria $(27,28)$

Viruses (13)

Bacteria (33)

Viruses $(34,35)$

Bacteria/viruses (13)
Effect of receptor/ligand

interaction
Induction of cytotoxicity and

cytokine release

Induction of cytotoxicity and

cytokine release

Induction of cytotoxicity and

cytokine release

Induction of cytotoxicity and

cytokine release

Induction of cytotoxicity and

cytokine release

Activation (cytokine/cytotoxicity)

Tumor cells (40)

Monocytes/neutrophils (48) (induced by

TLR engagement)

Tumor cells (39)

DC (47) (induced by TLR engagement)

Infected cells (44)

Infected cells (44)

Tumor cells (41)

Infected cells (42)

Induced on tumor cells (114)

N.D.

BCG (29)

Trophoblasts $(73,74)$

Tumor cells $(14,37)$

Infected cells $(38,44)$

CMV-infected DC (51)

Infected tumor cells (115)

Trophoblasts $(73,74)$

Activation/regulation?

Activation (cytokine/cytotoxicity)

Activation of NK/DC cross-talk

N.D.

Inhibition

Activation (cytokine/cytotoxicity)

Activation (cytokine/cytotoxicity)

Inhibition

IL-22 and TNF $\alpha$ release by ILC3

Supporting of NK cell activation

Activation (cytotoxicity)

Activation (cytokine/cytotoxicity)

Activation (cytokine/cytotoxicity)

Activation (cytokine/cytotoxicity)

Activation (cytokine/cytotoxicity)

Chemokine production by dNK

\section{(C) KIR}

2DL1

C2 epitope

2DL2/DL3

C1/C2 epitope; few HLA-B (C1 epitope)

2DL4

HLA-G

CpG ODN $(++)$

2DL5

N.D.

2DS1

C2 epitope

N.D.

N.D.

2DS3

N.D.

HLA-A11; some C1 and C2 HLA-C

2DS5

N.D.

3DL1

HLA-B and HLA-A (Bw4+)

CpG ODN $(+++)$

3DL2

HLA-A3, $-\mathrm{A} 11$

CpG ODN $(+++)$

3DL3 N.D.

3DS1

\section{Normal cells}

Normal cells

Normal cells

Infected cells?

N.D.

Normal cells; Tumor cells

N.D.

N.D.

Melanoma cell lines; primary melanoma

N.D.

N.D.

Normal cells

Infected cells?

Normal cells

Infected cells?

N.D.

Infected cells?

Infected cells?
Inhibition

Inhibition

Inhibition/IFN $\gamma$ induction

N.D.

Inhibition

Activation (cytokine/cytotoxicity)

N.D.

N.D.

Activation (cytokine/cytotoxicity) Activation (cytokine/cytotoxicity)

N.D.

Inhibition

N.D.

Inhibition

Activation (cytokine/cytotoxicity)

N.D.

N.D.

N.D.
CpG ODN $(+++)$

HIV-peptides?; HCV-peptides?

ECTV, ecteromelia virus; VV, vaccinia virus; NDV, new castle disease virus; dNK, decidual NK cells; N.D., not determined. 
after TLR3 stimulation), NK cells respond to dsRNA by improving their killing capabilities: not only against abnormal target cells, but also against immature DCs (iDCs) (13). This latter effect has been proposed as a mechanism by which NK cells can "edit" the process of DC maturation by selecting those DCs that are undergoing appropriate maturation and therefore would best prime $\mathrm{T}$ cells after migration to SLCs $(23,24)$. Moreover, upon the simultaneous stimulation by TLR3 engagement and IL12, NK cells also increase their capability of secreting pro-inflammatory cytokines, which mediate several important functions, including promotion of further DC maturation, anti-viral/anti-tumor effects, and induction of Th1 responses $(13,15,18)$.

Similar to DCs, NK cells also express TLR2, specific for products of bacterial origin (25). TLR2 is directly involved in the NK-mediated recognition of Mycobacterium tuberculosis (BCG) by NK cells (26-28). In turn, DCs, when exposed to BCG, release large amounts of IL12 that induce an amplification of the effector functions of NK cells. These include the enhancement of the NK cell cytotoxicity against both tumor cells and iDCs, and the cytokine release that can promote maturation of DCs, capable of inducing adaptive Th1 immune responses (27).

Moreover, the TLR2-mediated interaction of NK cells with BCG may induce the NK cell expression of NKp44, which, in turn, can directly bind to BCG (29). However, while TLR2 binding to Mycobacterium cell wall is sufficient to induce activation of $\mathrm{NK}$ cell effector functions (including IFN- $\gamma$ production), the engagement of NKp44 by BCG cell wall components may play a role in maintaining NK cell activation (28).

In addition, it has been recently demonstrated that TLR2 may be also involved in the NK-mediated response to human CMV (30).

Microbial unmethylated CpG DNA motifs are able to stimulate both NK cells and plasmacytoid DCs (pDCs) via TLR9, which is, indeed, expressed by both cell types. IFN- $\alpha$, released by pDCs upon TLR9 engagement, supports the triggering of TLR9-responsive NK cells $(31,32)$. This activation may be further amplified by IL12, released by DCs (31).

It has been reported that NK cells may also express TLR5. Flagellin, a typical TLR5 ligand, may directly act on NK cells, and induces the release of IFN- $\gamma$, contributing to activate surrounding cells, and $\alpha$-defensins, mediating pathogen destruction (33).

Human NK cells may also express functional TLR7 and TLR8 (34). In this context, it has been shown that NK cell stimulation by the TLR7/8 ligand ssRNA derived from HIV-1 depends on a direct contact between NK cells and pDCs or monocytes (35).

Thus, although NK cells can be directly activated by some TLR agonists, the microenvironment in which they lie, during TLR-mediated activation, may play an important role not only in the activation of their cytotoxic activity but also in their regulatory functions, able to modulate subsequent adaptive immune responses $(11,22,36)$.

\section{NATURAL CYTOTOXICITY RECEPTORS}

NKp46, NKp44, and NKp30 were among the first identified activating receptors on human NK cells. These structurally unrelated surface molecules were collectively defined as NCRs for their common ability to strongly activate NK cell cytolytic activity (37).
The generation of NCR-specific blocking monoclonal antibodies (mAbs) and the identification of an $\mathrm{NCR}^{\text {dim }}$-phenotype (with impaired NK-mediated tumor killing capabilities) in some individuals (14), rapidly allowed the demonstration that these receptors were recognizing ligands on a large array of NK-susceptible targets, primarily tumor cells. The first NCR ligands to be discovered, however, were of viral origin (38), while only recently some of the tumor-expressed cellular ligands (39-41) have been identified (Table 1B). Different viral hemagglutinins (HAs) bind one or more NCRs and trigger NK cell functions (42). The pressure exerted by NCRs on viruses is witnessed by the onset of specific escape mechanisms $(43,44)$. Thus, for example, the CMV-encoded pp65 molecule gives rise to intracellular inhibitory interaction with NKp30 (43) and the vaccinia virus HA has been recently shown to bind NKp30 and block NKp30-mediated activation (44). In addition, NK cells in HIV-infected patients may show various alterations, including a reduced expression and function of NCRs $(45,46)$.

The so far identified tumor-expressed NCR-ligands are represented by self-antigens whose expression/exposure at the outer cell surface can be induced by cell stress or activation, or by still unknown mechanisms related to tumor transformation (Table 1B). Thus, the NKp30-ligand HLA-B-associated transcript3/BCL-2-associated athanogene 6 (BAT3/BAG6) is a nuclear factor that can be released via exosomes and exposed at the cell surface by many tumor cells or, in response to stress, by DCs $(39,47)$. Another known ligand of NKp30, B7-H6, is expressed on transformed cells, and its expression can also be induced on normal cells (including monocytes and neutrophils) following stimulation with TLR ligands or pro-inflammatory cytokines $(40,48)$. Finally, an NKp44-ligand has been identified as an exon 21 specontaining isoform (21spe) of mixed lineage leukemia-5 (MLL5) protein. While the MLL5 is expressed in the nucleus of normal cells and is involved in the regulation of cell cycle and hematopoietic differentiation, the 21 spe-MLL5 is located in the cytoplasm and at the cell surface, where it cannot conceivably exert its physiologic function (41). Remarkably, this isoform appears to be exclusively transcribed in tumor cells.

Although it is presently unknown whether the tumorassociated NCR-ligands could also be induced by viral infections, there are evidences that certain viruses, such as filovirus or HIV, can promote the expression of still undefined NKp46- or NKp30ligands on DCs or T cells $(49,50)$ Moreover, CMV-infected DCs can activate NK cells via NKp46 and DNAM-1 (51). Intriguingly, the $\mathrm{mAb}$ recognizing 21 spe-MLL5 had been previously shown to react with $\mathrm{CD}^{+} \mathrm{T}$ cells treated with a specific peptide of HIV gp41 protein or derived from HIV-infected patients (50). Whatever could be the pathogenic process that mainly shapes the specificity of the NCRs, it is quite evident that these receptors are nevertheless involved in tumor surveillance in vivo. Experiments on NKp46KO mice support this evidence (52). In addition, various human studies have shown that both solid and hematologic malignancies can be frequently associated to the presence of NCR ${ }^{\text {dim }}$ NK cells (either in $\mathrm{PB}$ or at the tumor site) (53-56). In this context, different tumororchestrated mechanisms capable of suppressing NCR functionality have been described. Hypoxia, which frequently characterizes tumor tissues (57), or various factors produced by tumor cells or 
induced on by-stander cells, can down-regulate NCR expression or function. These factors include: IDO, TGF $\beta, \mathrm{PGE}_{2}$ (58-60), or inhibitory NCR-ligands, such as the soluble form of BAT3 (61), and the proliferating cell nuclear antigene (PCNA) (which has been recently shown to induce NKp44-mediated inhibitory signaling) (see also Table 1B).

Besides inducing natural cytotoxicity, the NCRs can also orchestrate regulatory functions. Indeed, since their first discovery, these receptors were known to induce cytokine release. In addition, in the early 2000s NK cells were shown to participate to regulatory interactions with DCs, pDCs, neutrophils, macrophages, and $\mathrm{T}$ cells, involving the engagement of various receptors including NKp30 and/or NKp46 (12, 58, 62-67). Finally, over the past 10-15 years, different NCR-expressing NK cell types, poorly cytolytic, and prominently devoted to regulatory functions, have been described. According to recent findings, these various NK cell types and the classical NK cells appear to be part of the larger family of innate lymphoid cells (ILCs), which show, as unifying trait, the expression of the transcriptional repressor Id2 during their development from a putative common hematopoietic precursor $(68,69)$. The different ILCs can be induced in selected tissues and are characterized by unique cytokine patterns and surface phenotypic profiles (including or not NK cell markers). Roughly, in both mice and humans, three groups of ILCs, ILC-group 1, 2, or 3, can be defined according to their ability to release Th1-, Th2-, or Th17/22-type cytokines respectively. NK or NK-like cells are comprised within group 1 and 3. The ILC-group 1 includes classical circulating CD56 ${ }^{\mathrm{dim}} \mathrm{CD} 16^{+} \mathrm{NK}$ cells, and CD56 ${ }^{\text {bright }}$ CD $16^{\text {dim }}$ cells (which prominently populate lymph nodes). Both these cell types can produce large amounts of IFN- $\gamma$ and TNF- $\alpha$ upon NCR engagement (6). The ILC-group 3 includes the $\mathrm{CD} 56^{+/-} \mathrm{NKp} 44^{+} \mathrm{NKp} 46^{+}$IL-22-producing NK-like cells $\left(\mathrm{NCR}^{+} \mathrm{ILC} 3\right)$, which populate mucosal tissues. $\mathrm{NCR}^{+}$ILC3 are not cytotoxic but, by producing cytokines including IL-22, maintain epithelial-cell barrier function and contrast bacterial dissemination. The role of NCR on these cells is still poorly defined, however, a recent report by Glazer et al. (70) indicated that NKp44 engagement could both induce TNF- $\alpha$ release and synergize with other cytokines to induce IL-22 production.

Another poorly cytotoxic NK cell population endowed with regulatory functions is represented by $\mathrm{CD} 56^{\text {bright }} \mathrm{CD} 16^{\mathrm{dim}} \mathrm{NCR}^{+}$ $\mathrm{NK}$ cells that populate the decidua in the first trimester of pregnancy. These cells produce defined pattern of cytokines, chemokines, and pro-angiogenic factors [favoring the appropriate placenta and fetus development (71)], and participate at the induction of tolerance at the maternal/fetal interface (72). The interaction with trophoblasts by the engagement of NCRs would activate their regulatory functions $(73,74)$. Thus, the definition of the above-described $\mathrm{NCR}^{+} \mathrm{NK}$ cell types, along with their new functions, would suggest that NCRs could recognize ligands expressed on different cells, to fulfill multiple tasks. In this context, for each receptor, different portions of the molecule and/or different polymorphism may have been shaped or selected to ensure the putative pleiotropy of NCRs (75-77).

\section{HLA-SPECIFIC RECEPTORS: KIRS}

Natural killer cells are equipped with inhibitory receptors able to interact specifically with human leukocyte antigen (HLA) class-I molecules on potential target cells. These receptors prevent NK cell-mediated attack against normal autologous cells and allow the killing of cells that upon tumor transformation or viral infection present compromised HLA class-I expression ("missing self hypothesis") (78) (Figure 1). In humans, two different types of HLA class-I-specific inhibitory receptors exist: (i) killer Ig-like receptors (KIRs), also referred to as CD158, that belong to the Ig-superfamily and, in most instances, recognize the polymorphic HLA-A, -B, and -C molecules (79-81), and (ii) CD94/NKG2A (CD94/CD159a), a heterodimer related to C-type lectins that recognizes HLA-E (82), a non-classical MHC molecule characterized by a limited polymorphism.

In addition, activating forms of KIRs have been also identified, but their specificity is still largely elusive (see relating paragraph). Related to the function performed, the intracytoplasmatic domains of KIRs can feature either a short (activating KIRs) or a long (inhibitory KIRs) cytoplasmic tail, " $\mathrm{S}$ " or " $\mathrm{L}$ " in the nomenclature, respectively $(79,83)$ (Table 1C).

Each individual may differ strongly in the activating KIR content. In particular, two different types of KIR haplotypes (A and B) can be distinguished in humans. Both haplotypes share inhibitory KIRs, but haplotype A (in 50\% of individuals) includes a single activating KIR (KIR2DS4) whereas haplotype B has up to five activating KIRs $(83,84)$. In general, haplotypes A are beneficial in NK responses to pathogens, whereas haplotypes $\mathrm{B}$ are associated with low frequencies of pregnancy disorders $(85,86)$.

In humans, $13 \mathrm{KIR}$ genes and 2 KIR pseudogenes (KIR2DP1 and 3DP1) are expressed. Three conserved genes (KIR3DL3, 2DL4, and 3DL2) form the common framework.

Only some of the 13 human KIRs have been demonstrated to recognize HLA class I. In contrast, no ligand has yet been identified for KIR2DS2, 2DS3, 2DS5, 2DL5, 3DS1, and 3DL3 (87)(Table 1C).

Regarding the Ig-domains content, each KIR displays two (KIR2D) or three (KIR3D) extracellular Ig-domains. Two types of KIR2D can be determined. KIR2D of the first type are composed by D1 and D2 domains and include the majority of KIRs (KIR2DL1/L2/L3 and KIR2DS1/S2/S3/S4/S5), whereas KIR2D of the second type are composed by D0 and D2 domains and include KIR2DL4/L5.

The high level of polymorphism in the KIR gene complex and the low conservation of KIR genes between species (only the three KIR genes KIR2DL4, KIR2DS4, KIR2DL5 have been preserved through hominid evolution) have suggested that KIRs have been undergone to a rapid evolution (87). Following this process, new KIR alleles, generated from existing ones under evolutionary pressure, are likely maintained when providing advantages (88).

A clear diversity in the KIR gene complex between modern populations indicates that geographically distinct diseases have recently exerted a selection on KIR repertoires (89).

In addition, the KIR diversification is thought to be more rapid than HLA diversification. Indeed, HLA genes are more similar in humans and chimpanzees than their KIR counterparts. In humans, HLA-C seems to have evolved as a superior and more specialized ligand for KIRs as compared to HLA-A and -B. This fact is supported by two considerations: (i) all HLA-C allotypes are KIR ligands, whereas only $45 \%$ of HLA-A and $36 \%$ of HLA-B allotypes are recognized by KIRs and (ii) HLA-C is of more recent origin as compared to HLA-A and -B $(90,91)$. 


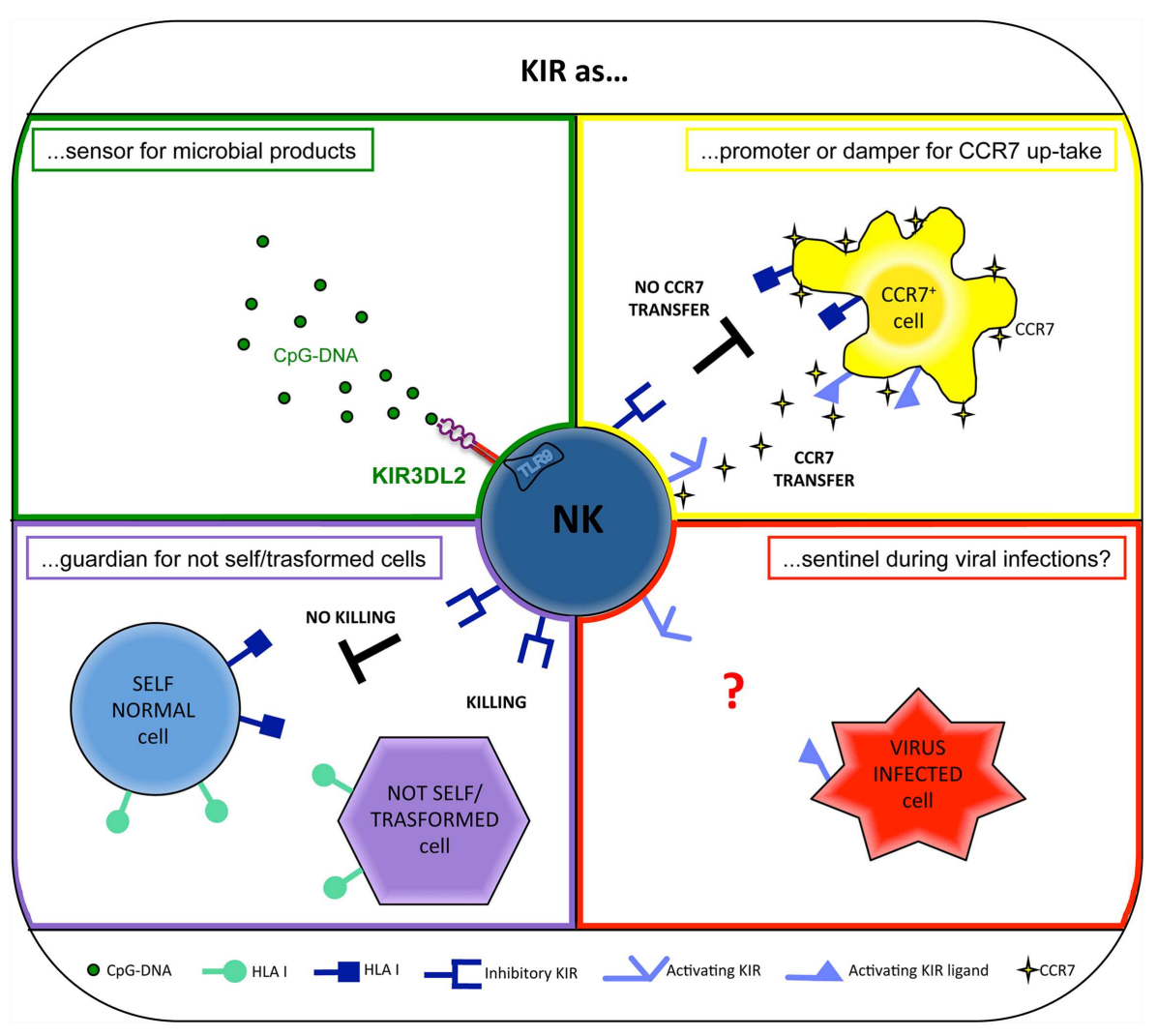

FIGURE 1 | Different roles for KIRs

\section{KIRS AS SENSOR FOR MICROBIAL PRODUCTS}

Recently, KIRs have been shown to exert a novel and surprising function. Indeed, primarily KIR3DL2 (but also other KIRs, including KIR3DL1, KIR3DS1, and KIR2DL4) has been shown to work as sensors for microbial products and as chaperons for TLR9 ligands. In particular, KIR3DL2 can bind CpG ODNs at the NK cell surface and shuttle them to early endosomes where TLR9 translocates upon CpG ODN cell stimulation. In this intracellular compartment, KIR3DL2 gives CpG ODN to TLR9, thus allowing NK cell activation both in terms of increment of cytotoxicity and cytokine production $(11,19)$ (Figure 1).

The KIR Ig-domain involved in the direct recognition of microbial CpG ODN is represented by the D0, which is expressed by all the CpG ODN-binding KIRs. The interactions between negative charges of DNA sequences and positive charges of D0 domain probably are responsible for this binding. Remarkably, IFN- $\gamma$ release induced by $\mathrm{CpG}$ ODN stimulation was mostly confined to KIR3DL2 ${ }^{+}$NK cell subset, suggesting that this receptor may be more efficient in CpG ODN-shuttling and NK cell triggering than the other CpG ODN-binding KIRs (19).

In this context, it is worth noting that KIR3DL2 represents a framework gene (92) and, as a consequence, NK cells of all individuals can bind CpG ODN. This novel functional capability of KIR3DL2 may provide an important clue to understanding the driving forces that led to conservation of KIR3DL2-encoding gene in all haplotypes, in spite of the low frequency of its HLA ligands (HLA-A3 or -A11 alleles) (93) in the human population. Indeed, the need of rapid NK-mediated anti-microbial responses may represent an important factor of selective pressure. Moreover, KIR3DL2 is characterized by poor inhibitory capability because of its low affinity for HLA-A ligands. This weak inhibitory function may explain why KIR3DL2, in most NK cells, is coexpressed with other inhibitory KIRs or NKG2A (19).

Remarkably, some studies have indicated a three-domain surface molecule carrying a D0 domain as the putative ancestral mammalian KIR and have suggested that all KIR2D encoding genes have evolved from a KIR3D-encoding gene. Considering these evidences, it is possible to hypothesize that, in origin, certain KIRs could have a role different from that to recognize MHC-class-I molecules (94).

\section{ACTIVATING KIRS AS SENTINELS DURING VIRAL INFECTIONS?}

The main differences between activating and inhibitory HLAspecific receptors are located in their cytoplasmic tails. Indeed, the activating KIRs are characterized by a short cytoplasmic tail devoid of ITIMs and by a transmembrane domain with a charged amino-acid residue that allows association with an ITAM-bearing molecule $(79,95)$. The role of activating KIRs in immune response is still enigmatic and so far little information about it is available. Only for two of them (KIR2DS1 and KIR2DS4) the specificity for HLA class-I molecules has been demonstrated (96-100), despite 
their extracellular domains are characterized by a high degree of sequence homology with their inhibitory counterparts.

However, a number of experimental evidences suggest that activating KIRs may play a role in NK-mediated response against viral infections (Figure 1). In particular, protection against hepatitis $\mathrm{C}$ virus infection (101) and delayed progression to AIDS (102) have been described in individuals coexpressing the activating receptor KIR3DS1 and its putative ligand, HLA-Bw4 with an isoleucine at position 80 (HLA-Bw4-80I). In addition, high levels of degranulation by KIR3DS1 ${ }^{+} \mathrm{NK}$ cells in response to HIV-infected HLABw4-80I ${ }^{+} \mathrm{CD}^{+} \mathrm{T}$ cells (103) and a preferential expansion of ${\mathrm{KIR} 3 \mathrm{DS} 1^{+}}^{+} \mathrm{NK}$ cells in HLA-Bw4-80I ${ }^{+}$subjects during acute HIV1 infection $(104,105)$ have been observed. However, the direct physical interaction between KIR3DS1 and HLA-Bw4-80I has not been demonstrated (106).

Moreover, different studies have suggested that the activating KIRs may interact with HLA class I at a lower affinity than their inhibitory counterparts. However, during viral infections, their HLA affinity may be increased by the presentation of viral peptides, thus allowing NK-mediated killing of infected cells (105). Thus, activating KIRs function could be modulated by the nature of the HLA class I presented peptide. In this context, KIR2DS1 has been described to display a certain degree of peptide selectivity in its binding to HLA-Cw4 (97).

It has been also speculated that additional molecules, upregulated on target cells upon cellular stress/transformation, may also favor the triggering signals delivered by activating KIRs, acting as costimuli, or as non-HLA class-I ligands for these receptors. Notably, KIR2DS4 is able to interact with a non-HLA classI protein expressed on melanoma cell lines and on a primary melanoma (107).

In some individuals, the increment in the signals generated by the low-affinity activating KIRs may overcome normal NK cell self-tolerance, thus inducing autoimmune diseases (108).

\section{KIR AS A PROMOTER OR DAMPER FOR A PHENOTYPE CHANGE}

Since cellular function is often linked to phenotype, it is of particular interest that the recent discovery of a mechanism by which NK cells would be able to capture target cell membrane components, and incorporate them in its own membrane, thus enriching their phenotypic/functional features (109). This process, known as trogocytosis, involves several cell-surface molecules in different cell types including lymphocytes as well as DCs and tumor cells and may represent a vector for rapid intercellular communication (110). The capture of target cell membrane fragments by NK cells is likely to reflect specific ligand recognition by $\mathrm{NK}$ cell receptors and, in particular, activating and inhibitory receptors control this process. Importantly, surface molecules acquired from other cell types could modify not only phenotypic but also functional characteristics of the recipient cells (111).

Through this mechanism, some peculiar characteristics of the two major NK cell subsets (CD56 dim/CD56 bright) (10) can be subverted. In this context, recently, it has been shown that the highly cytotoxic $\mathrm{CD} 56^{\mathrm{dim}} \mathrm{KIR}^{+} \mathrm{NK}$ cell subpopulation that is characterized by the $\mathrm{CCR}^{-}$phenotype, can acquire surface CCR7 upon interaction with $\mathrm{CCR}^{+}$cells, becoming able to migrate in response to the SLC chemokines CCL19/CCL21 (7).

This novel NK cell ability occurs via the immunological synapse, precedes the NK-mediated cytolysis, and is finely controlled by the specific interaction between KIRs on NK cells and HLA class-I molecules on CCR7 ${ }^{+}$cells. In particular, inhibitory KIRs block this transfer (7), whereas activating KIRs (e.g., KIR2DS1) are able to strongly promote the CCR7 acquisition by NK cells $(8,20)$. In addition, other surface NK receptors, including the NCR NKp46, may play a crucial role in promoting this phenomenon (7). Therefore, in some individuals, collaboration between activating KIRs and other non-HLA-specific triggering receptors may occur to further potentiate the CCR7 acquisition.

Remarkably, unlike the non-HLA-specific receptors (whose function could be limited by inhibitory signals delivered by both KIRs/NKG2A receptors), KIR2DS1 could promote CCR7 uptake even in NKG2A ${ }^{+}$NK cells, since the KIR2DS1-dependent uptake of CCR7 can override the inhibition provided by this receptor. This event allows a substantial expansion of the NK cell fraction capable of migrating to lymph nodes (20).

The key role of KIRs during the CCR7 transfer has important implications during haploidentical hematopoietic stem cell transplantation, in which donor-derived alloreactive NK cells expressing KIRs may play a relevant role in preventing graft vs. host disease (by killing recipient DCs) and host vs. graft reactions (by killing recipient T cells) (112). However, because $\mathrm{KIR}^{+} \mathrm{NK}$ cells normally do not express CCR7, it was unclear how alloreactive $\mathrm{KIR}^{+} \mathrm{NK}$ cells could reach lymph nodes and kill these cells directly in this compartment. In this context, the CCR7 acquisition by trogocytosis may represent a new way by which alloreactive $\mathrm{KIR}^{+} \mathrm{NK}$ cells can migrate to the site where they can kill mature DCs and T cell blasts (20, 113) (Figure 1).

\section{CONCLUSION}

Several data have demonstrated that the different NK cell receptors can reciprocally coordinate and regulate their functions, contributing to the initiation of innate responses and to the subsequent priming of adaptive immune responses. NK cell activation may be mediated by the engagement of TLRs and/or NCRs, two different types of receptors that may cooperate in inducing NK cell triggering, and thus in controlling viral/bacterial infection and cancer. For example, it has been demonstrated that TLR2 and NKp44 are directly involved in the recognition of Mycobacterium and in the consequent promotion of NK cell effector functions (28).

Natural killer cell triggering is under the control of receptors (e.g., KIRs) specific for self-HLA class-I molecules. The missing recognition of specific HLA ligands by inhibitory KIRs enables NK cell triggering upon NCRs engagement (37). Most tumor cellsurface ligands for NCRs have remained elusive; however, a critical role for NCRs in the control of both tumors and viral infections has been clearly demonstrated.

On the other hand, collaboration between TLRs and KIRs may also exist. Indeed, certain KIRs can function as sensor for microbial products and as chaperons for TLR9 ligands. Remarkably, an inhibitory KIR, such as KIR3DL2, may unexpectedly induce NK cell activation, favoring TLR-mediated response (19). 


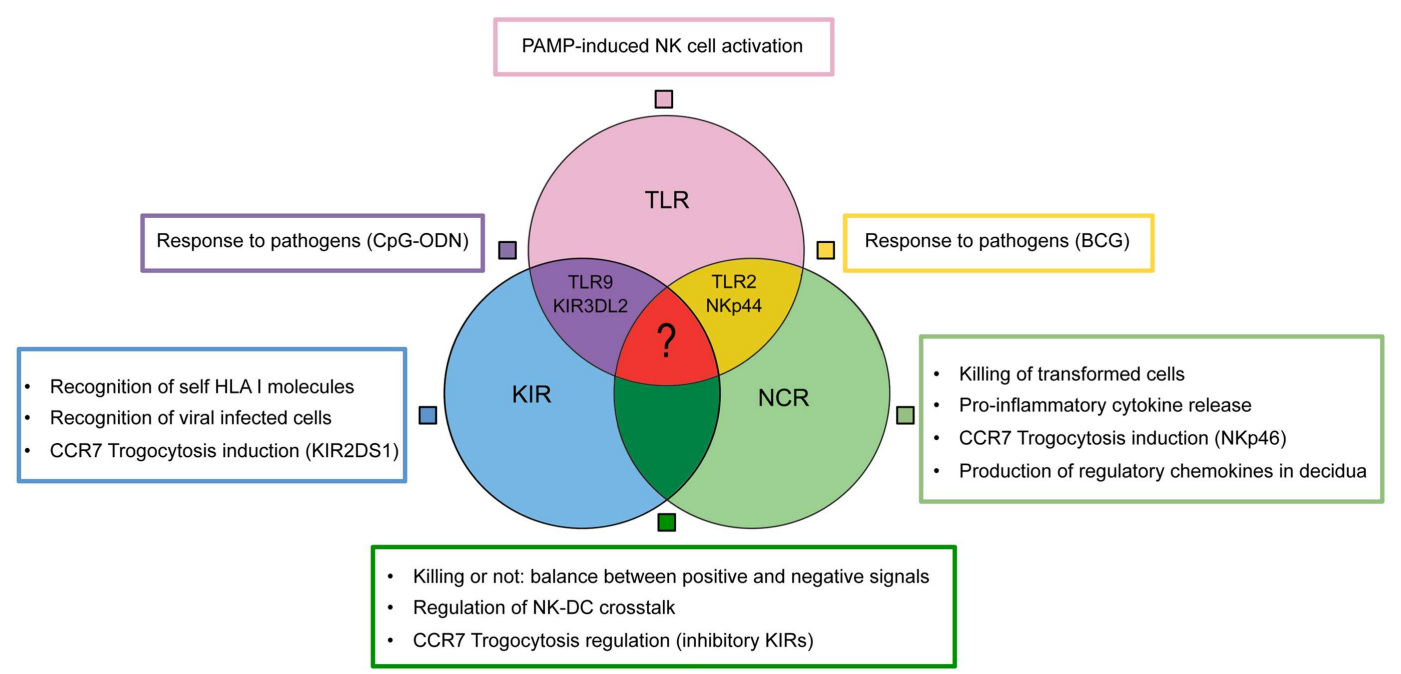

FIGURE 2 | Collaboration model between TLRs, KIRs, NCRs for NK cell activation

Activating and inhibitory NK receptors control other important mechanisms, such as trogocytosis, by which NK cells can modify their phenotypic/functional features. For example, $\mathrm{KIR}^{+} \mathrm{NK}$ cells can acquire CCR7 and thus migratory properties toward SLCs, by interacting with $\mathrm{CCR}^{+}$cells (e.g., mature DCs). This process is blocked by inhibitory KIRs and promoted by NCRs and, even further, by activating KIRs $(7,20)$.

The NK-mediated capability of releasing chemokines and cytokines in different compartments endowed NK cells with regulatory functions, affecting subsequent adaptive immune responses. In decidual tissues, the engagement of NCRs during NK-trophoblast interactions induces the release of regulatory chemokines, involved in tissue building and remodeling, and in the formation of new blood vessels (74).

In conclusion, a wide and heterogenous group of receptors allow NK cell to fulfill multifaceted functions (Figure 2). The nodes of this intricate functional network may represent new therapeutic targets in different pathological conditions including not only tumors or infections but also immune-mediated diseases or pregnancy failure.

\section{ACKNOWLEDGMENTS}

Supported by grants awarded by Associazione Italiana Ricerca per la Ricerca sul Cancro (AIRC) - Special Project $5 \times 1000$ no. 9962 (Alessandro Moretta; AIRC - IG project number 5282 (Massimo Vitale); $5 \times 1000$ Min. Sal. 2011 (Massimo Vitale); PRIN 2010 (Alessandro Moretta); Progetto di Ricerca Fondazione Carige 2013 (Emanuela Marcenaro); Progetto di Ricerca di Ateneo 2013 (Simona Sivori).

\section{REFERENCES}

1. Cerwenka A, Lanier LL. Natural killer cells, viruses and cancer. Nat Rev Immunol (2001) 1(1):41-9. doi:10.1038/35095564

2. Vivier E, Raulet DH, Moretta A, Caligiuri MA, Zitvogel L, Lanier LL, et al. Innate or adaptive immunity? The example of natural killer cells. Science (2011) 331(6013):44-9. doi:10.1126/science.1198687
3. Walzer T, Jaeger S, Chaix J, Vivier E. Natural killer cells: from CD3(-)NKp46(+) to post-genomics meta-analyses. Curr Opin Immunol (2007) 19(3):365-72. doi:10.1016/j.coi.2007.04.004

4. Moretta A, Marcenaro E, Parolini S, Ferlazzo G, Moretta L. NK cells at the interface between innate and adaptive immunity. Cell Death Differ (2008) 15(2):226-33. doi:10.1038/sj.cdd.4402170

5. Fauriat C, Long EO, Ljunggren HG, Bryceson YT. Regulation of human NK-cell cytokine and chemokine production by target cell recognition. Blood (2010) 115(11):2167-76. doi:10.1182/blood-2009-08-238469

6. De Maria A, Bozzano F, Cantoni C, Moretta L. Revisiting human natural killer cell subset function revealed cytolytic CD56(dim)CD16+ NK cells as rapid producers of abundant IFN-gamma on activation. Proc Natl Acad Sci U S A (2011) 108(2):728-32. doi:10.1073/pnas.1012356108

7. Marcenaro E, Cantoni C, Pesce S, Prato C, Pende D, Agaugue S, et al. Uptake of CCR7 and acquisition of migratory properties by human KIR+ NK cells interacting with monocyte-derived DC or EBV cell lines: regulation by KIR/HLAclass I interaction. Blood (2009) 114(19):4108-16. doi:10.1182/blood-200905-222265

8. Marcenaro E, Carlomagno S, Pesce S, Della Chiesa M, Moretta A, Sivori S. Role of alloreactive KIR2DS1(+) NK cells in haploidentical hematopoietic stem cell transplantation. J Leukoc Biol (2011) 90(4):661-7. doi:10.1189/jlb.0311137

9. Parolini S, Santoro A, Marcenaro E, Luini W, Massardi L, Facchetti F, et al. The role of chemerin in the colocalization of $\mathrm{NK}$ and dendritic cell subsets into inflamed tissues. Blood (2007) 109(9):3625-32. doi:10.1182/blood-2006-08038844

10. Cooper MA, Fehniger TA, Caligiuri MA. The biology of human natural killer-cell subsets. Trends Immunol (2001) 22(11):633-40. doi:10.1016/S14714906(01)02060-9

11. Marcenaro E, Carlomagno S, Pesce S, Moretta A, Sivori S. Bridging innate NK cell functions with adaptive immunity. Adv Exp Med Biol (2011) 780:45-55. doi:10.1007/978-1-4419-5632-3_5

12. Marcenaro E, Dondero A, Moretta A. Multi-directional cross-regulation of NK cell function during innate immune responses. Transpl Immunol (2006) 17(1):16-9. doi:10.1016/j.trim.2006.09.019

13. Sivori S, Falco M, Della Chiesa M, Carlomagno S, Vitale M, Moretta L, et al. CpG and double-stranded RNA trigger human NK cells by toll-like receptors: induction of cytokine release and cytotoxicity against tumors and dendritic cells. Proc Natl Acad Sci U S A (2004) 101(27):10116-21. doi:10.1073/pnas. 0403744101

14. Sivori S, Pende D, Bottino C, Marcenaro E, Pessino A, Biassoni R, et al. NKp46 is the major triggering receptor involved in the natural cytotoxicity of fresh or cultured human NK cells. Correlation between surface density of NKp46 and natural cytotoxicity against autologous, allogeneic or xenogeneic target cells. 
Eur J Immunol (1999) 29(5):1656-66. doi:10.1002/(SICI)1521-4141(199905) 29:05<1656::AID-IMMU1656>3.0.CO;2-1

15. Moretta A, Marcenaro E, Sivori S, Della Chiesa M, Vitale M, Moretta L. Early liaisons between cells of the innate immune system in inflamed peripheral tissues. Trends Immunol (2005) 26(12):668-75. doi:10.1016/j.it.2005.09.008

16. Gerosa F, Baldani-Guerra B, Nisii C, Marchesini V, Carra G, Trinchieri G. Reciprocal activating interaction between natural killer cells and dendritic cells. J Exp Med (2002) 195(3):327-33. doi:10.1084/jem.20010938

17. Marcenaro E, Ferranti B, Moretta A. NK-DC interaction: on the usefulness of auto-aggression. Autoimmun Rev (2005) 4(8):520-5. doi:10.1016/j.autrev. 2005.04.015

18. Marcenaro E, Carlomagno S, Pesce S, Della Chiesa M, Parolini S, Moretta A, et al. NK cells and their receptors during viral infections. Immunotherapy (2011) 3(9):1075-86. doi:10.2217/imt.11.99

19. Sivori S, Falco M, Carlomagno S, Romeo E, Soldani C, Bensussan A, et al. A novel KIR-associated function: evidence that CpG DNA uptake and shuttling to early endosomes is mediated by KIR3DL2. Blood (2010) 116(10):1637-47. doi:10.1182/blood-2009-12-256586

20. Marcenaro E, Pesce S, Sivori S, Carlomagno S, Moretta L, Moretta A. KIR2DS1dependent acquisition of CCR7 and migratory properties by human NK cells interacting with allogeneic HLA-C2+ DCs or T-cell blasts. Blood (2013) 121(17):3396-401. doi:10.1182/blood-2012-09-458752

21. Akira $S$, Uematsu S, Takeuchi O. Pathogen recognition and innate immunity. Cell (2006) 124(4):783-801. doi:10.1016/j.cell.2006.02.015

22. Kawai T, Akira $S$. The role of pattern-recognition receptors in innate immunity: update on toll-like receptors. Nat Immunol (2010) 11(5):373-84. doi:10.1038/ ni. 1863

23. Della Chiesa M, Vitale M, Carlomagno S, Ferlazzo G, Moretta L, Moretta A. The natural killer cell-mediated killing of autologous dendritic cells is confined to a cell subset expressing CD94/NKG2A, but lacking inhibitory killer Ig-like receptors. Eur J Immunol (2003) 33(6):1657-66. doi:10.1002/eji.200323986

24. Moretta A. Natural killer cells and dendritic cells: rendezvous in abused tissues. Nat Rev Immunol (2002) 2(12):957-64. doi:10.1038/nri956

25. Becker I, Salaiza N, Aguirre M, Delgado J, Carrillo-Carrasco N, Kobeh LG, et al. Leishmania lipophosphoglycan (LPG) activates NK cells through toll-like receptor-2. Mol Biochem Parasitol (2003) 130(2):65-74. doi:10.1016/S01666851(03)00160-9

26. Esin S, Batoni G, Pardini M, Favilli F, Bottai D, Maisetta G, et al. Functional characterization of human natural killer cells responding to Mycobacterium bovis bacille Calmette-Guerin. Immunology (2004) 112(1):143-52. doi:10.1111/j.1365-2567.2004.01858.x

27. Marcenaro E, Ferranti B, Falco M, Moretta L, Moretta A. Human NK cells directly recognize Mycobacterium bovis via TLR2 and acquire the ability to kill monocyte-derived DC. Int Immunol (2008) 20(9):1155-67. doi:10.1093/ intimm/dxn073

28. Esin S, Counoupas C, Aulicino A, Brancatisano FL, Maisetta G, Bottai D, et al. Interaction of Mycobacterium tuberculosis cell wall components with the human natural killer cell receptors NKp44 and toll-like receptor 2. Scand J Immunol (2013) 77(6):460-9. doi:10.1111/sji.12052

29. Esin S, Batoni G, Counoupas C, Stringaro A, Brancatisano FL, Colone M, et al. Direct binding of human NK cell natural cytotoxicity receptor NKp44 to the surfaces of mycobacteria and other bacteria. Infect Immun (2008) 76(4):1719-27. doi:10.1128/IAI.00870-07

30. Muntasell A, Costa-Garcia M, Vera A, Marina-Garcia N, Kirschning CJ, LopezBotet M. Priming of NK cell anti-viral effector mechanisms by direct recognition of human cytomegalovirus. Front Immunol (2013) 4:40. doi:10.3389/ fimmu.2013.00040

31. Della Chiesa M, Romagnani C, Thiel A, Moretta L, Moretta A. Multidirectional interactions are bridging human NK cells with plasmacytoid and monocyte-derived dendritic cells during innate immune responses. Blood (2006) 108(12):3851-8. doi:10.1182/blood-2006-02-004028

32. Sivori S, Carlomagno S, Moretta L, Moretta A. Comparison of different CpG oligodeoxynucleotide classes for their capability to stimulate human NK cells. Eur J Immunol (2006) 36(4):961-7. doi:10.1002/eji.200535781

33. Chalifour A, Jeannin P, Gauchat JF, Blaecke A, Malissard M, N'Guyen T, et al. Direct bacterial protein PAMP recognition by human NK cells involves TLRs and triggers alpha-defensin production. Blood (2004) 104(6):1778-83. doi:10.1182/blood-2003-08-2820
34. Hart OM, Athie-Morales V, O'Connor GM, Gardiner CM. TLR7/8-mediated activation of human NK cells results in accessory cell-dependent IFN-gamma production. J Immunol (2005) 175(3):1636-42.

35. Alter G, Suscovich TJ, Teigen N, Meier A, Streeck H, Brander C, et al. Singlestranded RNA derived from HIV-1 serves as a potent activator of NK cells. J Immunol (2007) 178(12):7658-66.

36. Marcenaro E, Della Chiesa M, Bellora F, Parolini S, Millo R, Moretta L, et al. IL12 or IL-4 prime human NK cells to mediate functionally divergent interactions with dendritic cells or tumors. J Immunol (2005) 174(7):3992-8.

37. Moretta A, Bottino C, Vitale M, Pende D, Cantoni C, Mingari MC, et al. Activating receptors and coreceptors involved in human natural killer cellmediated cytolysis. Annu Rev Immunol (2001) 19:197-223. doi:10.1146/ annurev.immunol.19.1.197

38. Mandelboim O, Lieberman N, Lev M, Paul L, Arnon TI, Bushkin Y, et al. Recognition of haemagglutinins on virus-infected cells by NKp46 activates lysis by human NK cells. Nature (2001) 409(6823):1055-60. doi:10.1038/ 35059110

39. Pogge von Strandmann E, Simhadri VR, von Tresckow B, Sasse S, Reiners KS, Hansen HP, et al. Human leukocyte antigen-B-associated transcript 3 is released from tumor cells and engages the NKp30 receptor on natural killer cells. Immunity (2007) 27(6):965-74. doi:10.1016/j.immuni.2007.10.010

40. Brandt CS, Baratin M, Yi EC, Kennedy J, Gao Z, Fox B, et al. The B7 family member B7-H6 is a tumor cell ligand for the activating natura killer cell receptor NKp30 in humans. J Exp Med (2009) 206(7):1495-503. doi:10.1084/jem.20090681

41. Baychelier F, Sennepin A, Ermonval M, Dorgham K, Debre P, Vieillard V. Identification of a cellular ligand for the natural cytotoxicity receptor NKp44. Blood (2013) 122(17):2935-42. doi:10.1182/blood-2013-03-489054

42. Brusilovsky M, Rosental B, Shemesh A, Appel MY, Porgador A. Human NK cell recognition of target cells in the prism of natural cytotoxicity receptors and their ligands. J Immunotoxicol (2012) 9(3):267-74. doi:10.3109/1547691X. 2012.675366

43. Arnon TI, Achdout H, Levi O, Markel G, Saleh N, Katz G, et al. Inhibition of the NKp30 activating receptor by pp65 of human cytomegalovirus. Nat Immunol (2005) 6(5):515-23. doi:10.1038/ni1190

44. Jarahian M, Fiedler M, Cohnen A, Djandji D, Hammerling GJ, Gati C, et al. Modulation of NKp30- and NKp46-mediated natural killer cell responses by poxviral hemagglutinin. PLoS Pathog (2011) 7(8):e1002195. doi:10.1371/ journal.ppat.1002195

45. De Maria A, Fogli M, Costa P, Murdaca G, Puppo F, Mavilio D, et al. The impaired NK cell cytolytic function in viremic HIV-1 infection is associated with a reduced surface expression of natural cytotoxicity receptors (NKp46, NKp30 and NKp44). Eur J Immunol (2003) 33(9):2410-8. doi:10.1002/eji. 200324141

46. Mavilio D, Benjamin J, Daucher M, Lombardo G, Kottilil S, Planta MA, et al. Natural killer cells in HIV-1 infection: dichotomous effects of viremia on inhibitory and activating receptors and their functional correlates. Proc Nat Acad Sci U S A (2003) 100(25):15011-6. doi:10.1073/pnas.2336091100

47. Simhadri VR, Reiners KS, Hansen HP, Topolar D, Simhadri VL, Nohroudi $\mathrm{K}$, et al. Dendritic cells release HLA-B-associated transcript-3 positive exosomes to regulate natural killer function. PLoS One (2008) 3(10):e3377. doi:10.1371/journal.pone.0003377

48. Matta J, Baratin M, Chiche L, Forel JM, Cognet C, Thomas G, et al. Induction of B7-H6, a ligand for the natural killer cell-activating receptor NKp30, in inflammatory conditions. Blood (2013) 122(3):394-404. doi:10.1182/blood2013-01-481705

49. Fuller CL, Ruthel G, Warfield KL, Swenson DL, Bosio CM, Aman MJ, et al. NKp30-dependent cytolysis of filovirus-infected human dendritic cells. Cell Microbiol (2007) 9(4):962-76. doi:10.1111/j.1462-5822.2006.00844.x

50. Vieillard V, Strominger JL, Debre P. NK cytotoxicity against CD4+ T cells during HIV-1 infection: a gp41 peptide induces the expression of an NKp44 ligand. Proc Natl Acad Sci U S A (2005) 102(31):10981-6. doi:10.1073/pnas. 0504315102

51. Magri G, Muntasell A, Romo N, Saez-Borderias A, Pende D, Geraghty DE, et al. NKp46 and DNAM-1 NK-cell receptors drive the response to human cytomegalovirus-infected myeloid dendritic cells overcoming viral immune evasion strategies. Blood (2011) 117(3):848-56. doi:10.1182/blood-2010-08301374 
52. Elboim M, Gazit R, Gur C, Ghadially H, Betser-Cohen G, Mandelboim O. Tumor immunoediting by NKp46. J Immunol (2010) 184(10):5637-44. doi:10.4049/jimmunol.0901644

53. Costello RT, Sivori S, Marcenaro E, Lafage-Pochitaloff M, Mozziconacci MJ, Reviron D, et al. Defective expression and function of natural killer celltriggering receptors in patients with acute myeloid leukemia. Blood (2002) 99(10):3661-7. doi:10.1182/blood.V99.10.3661

54. Baier C, Fino A, Sanchez C, Farnault L, Rihet P, Kahn-Perles B, et al. Natural killer cells modulation in hematological malignancies. Front Immunol (2013) 4:459. doi:10.3389/fimmu.2013.00459

55. Rocca YS, Roberti MP, Arriaga JM, Amat M, Bruno L, Pampena MB, et al. Altered phenotype in peripheral blood and tumor-associated NK cells from colorectal cancer patients. Innate Immun (2013) 19(1):76-85. doi:10.1177/ 1753425912453187

56. Platonova S, Cherfils-Vicini J, Damotte D, Crozet L, Vieillard V, Validire $\mathrm{P}$, et al. Profound coordinated alterations of intratumoral NK cell phenotype and function in lung carcinoma. Cancer Res (2011) 71(16):5412-22. doi:10.1158/0008-5472.CAN-10-4179

57. Balsamo M, Manzini C, Pietra G, Raggi F, Blengio F, Mingari MC, et al. Hypoxia downregulates the expression of activating receptors involved in NK-cellmediated target cell killing without affecting ADCC. Eur J Immunol (2013) 43(10):2756-64. doi:10.1002/eji.201343448

58. Della Chiesa M, Carlomagno S, Frumento G, Balsamo M, Cantoni C, Conte R, et al. The tryptophan catabolite L-kynurenine inhibits the surface expression of NKp46- and NKG2D-activating receptors and regulates NK-cell function. Blood (2006) 108(13):4118-25. doi:10.1182/blood-2006-03-006700

59. Castriconi R, Cantoni C, Della Chiesa M, Vitale M, Marcenaro E, Conte R, et al. Transforming growth factor beta 1 inhibits expression of NKp30 and NKG2D receptors: consequences for the NK-mediated killing of dendritic cells. Proc Natl Acad Sci U S A (2003) 100(7):4120-5. doi:10.1073/pnas.0730640100

60. Balsamo M, Scordamaglia F, Pietra G, Manzini C, Cantoni C, Boitano M, et al. Melanoma-associated fibroblasts modulate NK cell phenotype and antitumor cytotoxicity. Proc Natl Acad Sci U S A (2009) 106(49):20847-52. doi:10.1073/pnas.0906481106

61. Reiners KS, Topolar D, Henke A, Simhadri VR, Kessler J, Sauer M, et al. Soluble ligands for NK cell receptors promote evasion of chronic lymphocytic leukemia cells from NK cell anti-tumor activity. Blood (2013) 121(18):3658-65. doi:10.1182/blood-2013-01-476606

62. Vitale M, Della Chiesa M, Carlomagno S, Pende D, Arico M, Moretta L, et al. NK-dependent DC maturation is mediated by TNFalpha and IFNgamma released upon engagement of the NKp30 triggering receptor. Blood (2005) 106(2):566-71. doi:10.1182/blood-2004-10-4035

63. Scordamaglia F, Balsamo M, Scordamaglia A, Moretta A, Mingari MC, Canonica GW, et al. Perturbations of natural killer cell regulatory functions in respiratory allergic diseases. J Allergy Clin Immunol (2008) 121(2):479-85. doi:10.1016/j.jaci.2007.09.047

64. Crome SQ, Lang PA, Lang KS, Ohashi PS. Natural killer cells regulate diverse T cell responses. Trends Immunol (2013) 34(7):342-9. doi:10.1016/j.it.2013.03. 002

65. Bellora F, Castriconi R, Dondero A, Reggiardo G, Moretta L, Mantovani A, et al. The interaction of human natural killer cells with either unpolarized or polarized macrophages results in different functional outcomes. Proc Natl Acad Sci U S A (2010) 107(50):21659-64. doi:10.1073/pnas.1007654108

66. Agaugue S, Marcenaro E, Ferranti B, Moretta L, Moretta A. Human natural killer cells exposed to IL-2, IL-12, IL-18, or IL-4 differently modulate priming of naive $\mathrm{T}$ cells by monocyte-derived dendritic cells. Blood (2008) 112(5):1776-83. doi:10.1182/blood-2008-02-135871

67. Thoren FB, Riise RE, Ousback J, Della Chiesa M, Alsterholm M, Marcenaro E, et al. Human NK cells induce neutrophil apoptosis via an NKp46- and Fas-dependent mechanism. J Immunol (2012) 188(4):1668-74. doi:10.4049/ jimmunol.1102002

68. Spits H, Di Santo JP. The expanding family of innate lymphoid cells: regulators and effectors of immunity and tissue remodeling. Nat Immunol (2011) 12(1):21-7. doi:10.1038/ni.1962

69. Spits H, Artis D, Colonna M, Diefenbach A, Di Santo JP, Eberl G, et al. Innate lymphoid cells - a proposal for uniform nomenclature. Nat Rev Immunol (2013) 13(2):145-9. doi:10.1038/nri3365
70. Glatzer T, Killig M, Meisig J, Ommert I, Luetke-Eversloh M, Babic M, et al. RORgammat(+) innate lymphoid cells acquire a proinflammatory program upon engagement of the activating receptor NKp44. Immunity (2013) 38(6):1223-35. doi:10.1016/j.immuni.2013.05.013

71. Hanna J, Goldman-Wohl D, Hamani Y, Avraham I, Greenfield C, NatansonYaron S, et al. Decidual NK cells regulate key developmental processes at the human fetal-maternal interface. Nat Med (2006) 12(9):1065-74. doi:10.1038/ nm 1452

72. Vacca P, Cantoni C, Vitale M, Prato C, Canegallo F, Fenoglio D, et al. Crosstalk between decidual NK and CD14+ myelomonocytic cells results in induction of Tregs and immunosuppression. Proc Natl Acad Sci U S A (2010) 107(26):11918-23. doi:10.1073/pnas.1001749107

73. Sivori S, Parolini S, Marcenaro E, Millo R, Bottino C, Moretta A. Triggering receptors involved in natural killer cell-mediated cytotoxicity against choriocarcinoma cell lines. Hum Immunol (2000) 61(11):1055-8. doi:10.1016/S01988859(00)00201-9

74. Vacca P, Cantoni C, Prato C, Fulcheri E, Moretta A, Moretta L, et al. Regulatory role of NKp44, NKp46, DNAM-1 and NKG2D receptors in the interaction between NK cells and trophoblast cells. Evidence for divergent functional profiles of decidual versus peripheral NK cells. Int Immunol (2008) 20(11):1395-405. doi:10.1093/intimm/dxn105

75. Li Y, Wang Q, Mariuzza RA. Structure of the human activating natural cytotoxicity receptor NKp30 bound to its tumor cell ligand B7-H6. J Exp Med (2011) 208(4):703-14. doi:10.1084/jem.20102548

76. Kaifu T, Escaliere B, Gastinel LN, Vivier E, Baratin M. B7-H6/NKp30 interaction: a mechanism of alerting NK cells against tumors. Cell Mol Life Sci (2011) 68(21):3531-9. doi:10.1007/s00018-011-0802-7

77. Delahaye NF, Rusakiewicz S, Martins I, Menard C, Roux S, Lyonnet L, et al. Alternatively spliced NKp30 isoforms affect the prognosis of gastrointestinal stromal tumors. Nat Med (2011) 17(6):700-7. doi:10.1038/nm.2366

78. Karre K. Natural killer cell recognition of missing self. Nat Immunol (2008) 9(5):477-80. doi:10.1038/ni0508-477

79. Moretta A, Bottino C, Vitale M, Pende D, Biassoni R, Mingari MC, et al. Receptors for HLA class-I molecules in human natural killer cells. Annu Rev Immunol (1996) 14:619-48. doi:10.1146/annurev.immunol.14.1.619

80. Lanier LL. NK cell receptors. Annu Rev Immunol (1998) 16:359-93. doi:10. 1146/annurev.immunol.16.1.359

81. Long EO. Regulation of immune responses through inhibitory receptors. Annu Rev Immunol (1999) 17:875-904. doi:10.1146/annurev.immunol.17.1.875

82. Braud VM, Allan DS, O'Callaghan CA, Soderstrom K, D’Andrea A, Ogg GS, et al. HLA-E binds to natural killer cell receptors CD94/NKG2A, B and C. Nature (1998) 391(6669):795-9.

83. Falco M, Moretta L, Moretta A, Bottino C. KIR and KIR ligand polymorphism: a new area for clinical applications? Tissue Antigens (2013) 82(6):363-73. doi: $10.1111 / \tan .12262$

84. Uhrberg M, Valiante NM, Shum BP, Shilling HG, Lienert-Weidenbach K, Corliss B, et al. Human diversity in killer cell inhibitory receptor genes. Immunity (1997) 7(6):753-63. doi:10.1016/S1074-7613(00)80394-5

85. Parham P, Moffett A. Variable NK cell receptors and their MHC class I ligands in immunity, reproduction and human evolution. Nat Rev Immunol (2013) 13(2):133-44. doi:10.1038/nri3370

86. Hiby SE, Apps R, Sharkey AM, Farrell LE, Gardner L, Mulder A, et al. Maternal activating KIRs protect against human reproductive failure mediated by fetal HLA-C2. J Clin Invest (2010) 120(11):4102-10. doi:10.1172/ JCI43998

87. Parham P, Norman PJ, Abi-Rached L, Guethlein LA. Human-specific evolution of killer cell immunoglobulin-like receptor recognition of major histocompatibility complex class I molecules. Philos Trans R Soc Lond B Biol Sci (2012) 367(1590):800-11. doi:10.1098/rstb.2011.0266

88. Akkaya M, Barclay AN. How do pathogens drive the evolution of paired receptors? Eur J Immunol (2013) 43(2):303-13. doi:10.1002/eji.201242896

89. Middleton D, Gonzelez F. The extensive polymorphism of KIR genes. Immunology (2010) 129(1):8-19. doi:10.1111/j.1365-2567.2009.03208.x

90. Older Aguilar AM, Guethlein LA, Adams EJ, Abi-Rached L, Moesta AK, Parham P. Coevolution of killer cell Ig-like receptors with HLA-C to become the major variable regulators of human NK cells. J Immunol (2010) 185(7):4238-51. doi:10.4049/jimmunol.1001494 
91. Older Aguilar AM, Guethlein LA, Hermes M, Walter L, Parham P. Rhesus macaque KIR bind human MHC class I with broad specificity and recognize HLA-C more effectively than HLA-A and HLA-B. Immunogenetics (2011) 63(9):577-85. doi:10.1007/s00251-011-0535-7

92. Wilson MJ, Torkar M, Haude A, Milne S, Jones T, Sheer D, et al. Plasticity in the organization and sequences of human KIR/ILT gene families. Proc Natl Acad Sci U S A (2000) 97(9):4778-83. doi:10.1073/pnas.080588597

93. Pende D, Biassoni R, Cantoni C, Verdiani S, Falco M, di Donato C, et al. The natural killer cell receptor specific for HLA-A allotypes: a novel member of the p58/p70 family of inhibitory receptors that is characterized by three immunoglobulin-like domains and is expressed as a 140-kDa disulphide-linked dimer. J Exp Med (1996) 184(2):505-18. doi:10.1084/jem.184.2.505

94. Sivori S, Falco M, Moretta L, Moretta A. Extending killer Ig-like receptor function: from HLA class I recognition to sensors of microbial products. Trends Immunol (2010) 31(8):289-94. doi:10.1016/j.it.2010.05.007

95. Olcese L, Cambiaggi A, Semenzato G, Bottino C, Moretta A, Vivier E. Human killer cell activatory receptors for MHC class I molecules are included in a multimeric complex expressed by natural killer cells. J Immunol (1997) 158(11):5083-6.

96. Moretta A, Sivori S, Vitale M, Pende D, Morelli L, Augugliaro R, et al. Existence of both inhibitory (p58) and activatory ( $\mathrm{p} 50)$ receptors for HLA-C molecules in human natural killer cells. J Exp Med (1995) 182(3):875-84. doi:10.1084/jem.182.3.875

97. Stewart CA, Laugier-Anfossi F, Vely F, Saulquin X, Riedmuller J, Tisserant A, et al. Recognition of peptide-MHC class I complexes by activating killer immunoglobulin-like receptors. Proc Natl Acad Sci U S A (2005) 102(37):13224-9. doi:10.1073/pnas.0503594102

98. Chewning JH, Gudme CN, Hsu KC, Selvakumar A, Dupont B. KIR2DS1positive NK cells mediate alloresponse against the C2 HLA-KIR ligand group in vitro. J Immunol (2007) 179(2):854-68.

99. Sivori S, Carlomagno S, Falco M, Romeo E, Moretta L, Moretta A. Natural killer cells expressing the KIR2DS1-activating receptor efficiently kill T-cell blasts and dendritic cells: implications in haploidentical HSCT. Blood (2011) 117(16):4284-92. doi:10.1182/blood-2010-10-316125

100. Graef T, Moesta AK, Norman PJ, Abi-Rached L, Vago L, Older Aguilar AM, et al. KIR2DS4 is a product of gene conversion with KIR3DL2 that introduced specificity for HLA-A 11 while diminishing avidity for HLA-C. J Exp Med (2009) 206(11):2557-72. doi:10.1084/jem.20091010

101. Khakoo SI, Thio CL, Martin MP, Brooks CR, Gao X, Astemborski J, et al. HLA and NK cell inhibitory receptor genes in resolving hepatitis $\mathrm{C}$ virus infection. Science (2004) 305(5685):872-4. doi:10.1126/science.1097670

102. Martin MP, Gao X, Lee JH, Nelson GW, Detels R, Goedert JJ, et al. Epistatic interaction between KIR3DS1 and HLA-B delays the progression to AIDS. Nat Genet (2002) 31(4):429-34. doi:10.1038/ng934

103. Alter G, Martin MP, Teigen N, Carr WH, Suscovich TJ, Schneidewind A, et al. Differential natural killer cell-mediated inhibition of HIV-1 replication based on distinct KIR/HLA subtypes. J Exp Med (2007) 204(12):3027-36. doi:10.1084/jem.20070695

104. Alter G, Altfeld M. NK cells in HIV-1 infection: evidence for their role in the control of HIV-1 infection. J Intern Med (2009) 265(1):29-42. doi:10.1111/j. 1365-2796.2008.02045.x

105. Alter G, Rihn S, Walter K, Nolting A, Martin M, Rosenberg ES, et al. HLA class I subtype-dependent expansion of KIR3DS1+ and KIR3DL1+ NK cells during acute human immunodeficiency virus type 1 infection. J Virol (2009) 83(13):6798-805. doi:10.1128/JVI.00256-09
106. Carr WH, Rosen DB, Arase H, Nixon DF, Michaelsson J, Lanier LL. Cutting edge: KIR3DS1, a gene implicated in resistance to progression to AIDS, encodes a DAP12-associated receptor expressed on NK cells that triggers NK cell activation. J Immunol (2007) 178(2):647-51.

107. Katz G, Gazit R, Arnon TI, Gonen-Gross T, Tarcic G, Markel G, et al. MHC class I-independent recognition of NK-activating receptor KIR2DS4. J Immunol (2004) 173(3):1819-25.

108. Iannello A, Debbeche O, Samarani S, Ahmad A. Antiviral NK cell responses in HIV infection. I. NK cell receptor genes as determinants of HIV resistance and progression to AIDS. J Leukoc Biol (2008) 84(1):1-26. doi:10.1189/jlb. 0907650

109. Tabiasco J, Espinosa E, Hudrisier D, Joly E, Fournie JJ, Vercellone A. Active trans-synaptic capture of membrane fragments by natural killer cells. Eur J Immunol (2002) 32(5):1502-8. doi:10.1002/1521-4141(200205)32:5<1502: :AID-IMMU1502>3.0.CO;2-Y

110. Davis DM. Intercellular transfer of cell-surface proteins is common and can affect many stages of an immune response. Nat Rev Immunol (2007) 7(3):238-43. doi:10.1038/nri2020

111. McCann FE, Eissmann P, Onfelt B, Leung R, Davis DM. The activating NKG2D ligand MHC class I-related chain A transfers from target cells to NK cells in a manner that allows functional consequences. J Immunol (2007) 178(6):3418-26.

112. Moretta L, Locatelli F, Pende D, Marcenaro E, Mingari MC, Moretta A. Killer Iglike receptor-mediated control of natural killer cell alloreactivity in haploidentical hematopoietic stem cell transplantation. Blood (2011) 117(3):764-71. doi:10.1182/blood-2010-08-264085

113. Somanchi SS, Somanchi A, Cooper LJ, Lee DA. Engineering lymph node homing of ex vivo-expanded human natural killer cells via trogocytosis of the chemokine receptor CCR7. Blood (2012) 119(22):5164-72. doi:10.1182/blood2011-11-389924

114. Rosental B, Brusilovsky M, Hadad U, Oz D, Appel MY, Afergan F, et al. Proliferating cell nuclear antigen is a novel inhibitory ligand for the natural cytotoxicity receptor NKp44. J Immunol (2011) 187(11):5693-702. doi:10.4049/jimmunol. 1102267

115. Jarahian M, Watzl C, Fournier P, Arnold A, Djandji D, Zahedi S, et al. Activation of natural killer cells by newcastle disease virus hemagglutinin-neuraminidase. J Virol (2009) 83(16):8108-21. doi:10.1128/JVI.00211-09

Conflict of Interest Statement: Alessandro Moretta is a founder and shareholder of Innate-Pharma (Marseille, France). The remaining authors declare no competing financial interests.

Received: 30 January 2014; accepted: 01 March 2014; published online: 19 March 2014. Citation: Sivori S, Carlomagno S, Pesce S, Moretta A, Vitale $M$ and Marcenaro E (2014) TLR/NCR/KIR: which one to use and when? Front. Immunol. 5:105. doi: 10.3389/fimmu.2014.00105

This article was submitted to NK Cell Biology, a section of the journal Frontiers in Immunology.

Copyright (c) 2014 Sivori, Carlomagno, Pesce, Moretta, Vitale and Marcenaro. This is an open-access article distributed under the terms of the Creative Commons Attribution License (CC BY). The use, distribution or reproduction in other forums is permitted, provided the original author(s) or licensor are credited and that the original publication in this journal is cited, in accordance with accepted academic practice. No use, distribution or reproduction is permitted which does not comply with these terms. 